\title{
INDONESIAN FAN GIRLS' PERCEPTION TOWARDS SOFT MASCULINITY AS REPRESENTED BY K-POP MALE IDOLS
}

\author{
Paramita Ayuningtyas \\ English Department, Faculty of Humanities, Bina Nusantara University \\ Jln. Kemanggisan Ilir III No. 45, Palmerah, Jakarta Barat 11480, Indonesia \\ ayu.palar@gmail.com,paramita@binus.ac.id
}

Received: $18^{\text {th }}$ November 2016/ Revised: $21^{\text {st }}$ December 2016/ Accepted: $4^{\text {th }}$ January 2017

How to Cite: Ayuningtyas, P. (2017). Indonesian Fan Girls' Perception towards Soft Masculinity as Represented By K-pop Male Idols. Lingua Cultura, 11(1). 53-57.

http://dx.doi.org/10.21512/lc.v11i1.1514

\begin{abstract}
This article aimed to examine how fan girls perceive this new form of masculinity represented by K-pop male idols (termed as soft masculinity). This research used a mixed method in collecting the data from a questionnaire distributed via e-mail and Line to twenty fan girls from various fandoms in April 2016. The result shows that the respondents are aware that in the entertainment business, gender identity can be modified and presented as a part of marketing strategy. In addition, they only see the soft masculinity delivered by K-pop male idols as a form of performance.
\end{abstract}

Keywords: Indonesian fan girls, self masculinity, K-pop, male idols

\section{INTRODUCTION}

Over the last decade, Korean pop music (commonly known as K-pop) has been a global phenomenon. As a part of Hallyu (Korean Wave, a movement that promotes Korean popular culture products such as drama, movies, and music), K-pop has gained tremendous popularity not only in Asia but also in other continents, such as America, Europe, and Australia. The groups from the second generation of K-pop like Super Junior and Big Bang have held world tours, including countries like Argentina, Mexico, England, and Australia. Their juniors from the third generation like EXO, BTS, and B.A.P have also successfully held concerts in America, Canada, and Germany. Social networking services highly contribute to this global popularity of K-pop (Jang \& Paik, 2012). Fans can easily watch K-pop videos in YouTube, buy the CDs from online shops, and get involved in fan activities on Twitter and Facebook.

What makes K-pop really popular and beat music scenes from other countries? Fuhr (2015) has argued that K-pop manages to go global because of several reasons, some of which are group names that can be easily understood by the non-Korean audience, use of English in the lyrics, and fans' participation in translating lyrics, interview, and articles to eliminate the linguistic boundaries. Meanwhile, Kim has stated that hybrid characters in K-pop are significant factors of its popularity (Bok-rae, 2015). For instance, the music is heavily influenced by Western popular music but can be combined with Korean traditional music (such as B.A.P's No Mercy and TOPP DOGG's Arario that use Korean traditional drums for the beat). These hybrid characters can also be viewed in the gender representation of the male idols, which can be called as hybrid masculinity.

$\mathrm{K}$-pop is a music genre that relies profoundly on visual, as shown by the eye-catching fashion, the meticulous production of music videos, and the synchronized choreographies. The importance of visual can also be witnessed in the necessity to release teaser images before actually releasing the album or the music videos. When it comes to physical appearance, the male idols are as groomed as the female idols, up to the point that they are viewed as pretty as (and in some cases, even prettier) the female idols. Sun Jung (Tunstall, 2014) has defined this as East Asian soft masculinity. She has said that soft masculinity is a hybrid product constructed through the amalgamation of South Korea's traditional seonbi masculinity (which is influenced by Chinese Confucian wen masculinity), Japan's bishonen (pretty boy) and global metrosexual masculinity. Masculinity in K-pop seems to be in contrast with Korean traditional masculinity that defined by patriarchal authoritarian masculinity, hard masculinity rooted in compulsory military service for men and true seonbi (Confucian, traditional masculinity referring to young noblemen) (Leung, 2012).

Related to the aforementioned soft masculinity of $\mathrm{K}$-pop, the writer interested to know how this new, nontraditional form of masculinity, is perceived by their fans, most of which are female. What do they think of soft masculinity? Do they see this as an effort to deconstruct gender categories? Or do they see this purely as a fan service and pure entertainment, or according to Judith Butler as 
performance? This study is designed and conducted to find the answer to those questions. Furthermore, this study is significant because, since 2011, Indonesia has become a big market target for K-pop that is shown by the number of K-pop concerts held in Indonesia. K-pop has built a massive fandom in Indonesia. It also hugely influences the fans' lifestyle (fashion and makeup) and even their option of university major (many fans want to study in South Korea). Currently, K-pop is a notable popular culture in Indonesia, and this article will have a contribution to the academic analysis of the study of the relationship between popular culture and gender representation.

Many types of research on K-pop fans have been conducted through various perspectives. Otmazgin \& Lyan (2014) have examined how K-pop fans in Israel and Palestine act as cultural mediators in their study (Hallyu across the Desert: K-pop Fandom in Israel and Palestine). Meanwhile, Kim, Mayasari, \& Oh (2013) have analyzed the phenomenon of tourist audiences in their paper "When Tourist Audience Encounter Each Other: Diverging Learning Behaviours of K-pop Fans from Japan and Indonesia". Through in-depth interviews with Japanese and Indonesian female K-pop fans, they conclude that fans from the two countries have different patterns of learning behavior. Different from the previous researches, this paper focuses on fans' reactions towards gender representation in K-pop, particularly how Indonesian fan girls view this nontraditional form of masculinity.

From general conception, masculinity is the quality of being a man. However, years of research in sociology, media studies, psychology, and other fields have shown the definition of masculinity is not as simple as that. The essentialists argue that masculinity is an entity embedded in male bodies, but Connell and Messerschmidt have an opposite opinion. They stated that masculinities are configurations of practice that are accomplished in social action and, therefore, can differ according to the gender relations in a particular social setting (Connell \& Messerschmidt, 2005). It is not a fixed substance in someone's biological features, but the result of social values, historical context, cultural struggles, and changes instead. Furthermore, Beynon (2002) has mentioned the key factors that shape masculinities, namely: historical location, age and physique, sexual orientation, education, status and lifestyle, geographical, ethnicity, religion and beliefs, class and occupation, culture and subculture. Masculinity is indeed a complex term.

Similar to feminists who now prefer to use the plural form 'feminisms' to replace the singular meaning of 'feminism', now academics tend to use the term 'masculinities' to refer to the variations of masculinity, in "how it is understood, enacted, experienced and lived" (Beynon, 2002). One of the examples of variations of masculinity is this concept called hegemonic masculinity. Connell (Beynon, 2002) has defined hegemonic masculinity as the most successful way to be a real man at a particular time in specific places. Hegemonic masculinity is constructed by applying either consensual mediation or power and achievement. Connell and Messerschmidt (2005) then added that hegemonic masculinity is normative. Besides containing the most correct way to be a man, it also ideologically allows the subordination of women to men. It can be said that hegemonic masculinity is a form of domination of men over women.

Masculinity is not a fixed concept; it changes over time and places. has noted that there are six aspects that influenced how masculinity was experienced in the 20th century; the rise of women, wars in the 20th century, changes in the world of work, the rise of consumerism and celebrity culture, the rise of the gay movement and changing views on masculinity. These affect how men think about themselves in personal and public spheres. Moreover, it leads to the so-called crisis in masculinity. Society now thinks that masculinity is damaging and out of fashion. However, Mangan has a different opinion about it, "Crisis is ... a condition of masculinity itself. Masculine gender identity is never stable; its terms are continually being re-defined and re-negotiated, the gender performance continually being restaged." (Beynon, 2002). Gender concept is fluid and will constantly change, and Mangan sees this as an unavoidable process. Instead of calling it as a crisis, men just have to find a new place for themselves in the changing modern world (Gauntlett, 2002) .

New and innovative ways are needed to research and theorize men and masculinities in the 21 st century. Beynon (2002) has offered six research models for this: (1) The literary, which focuses on how masculinity is depicted in literature; (2) Printed media, to see how masculinity is represented in newspapers and magazines; (3) Broadcast media, to analyze the representation of masculinity in film and on television; (4) Visual and performativity, which aims to see how masculinity is portrayed in photography, advertisements, appearance, pop music, etc.; (5) Auto/ biographical and documentary, to see how masculinity is portrayed and experienced in the past; and (6) Ethnographic, to analyze how masculinity is constructed in particular settings. This research will apply the fourth mode, to see how masculinity is represented in pop music and furthermore analyze how the audience views it.

\section{METHODS}

This research used a mixed method in collecting the data. The data of the research were collected from a questionnaire distributed via e-mail and Line to twenty fan girls from various fandoms in April 2016. When the writer found ambiguous or unclear answers, the writer conducted an in-depth interview to confirm and ask them to elaborate the answers. There was a total of six questions in the questionnaire with questions focusing on their perception towards soft masculinity as represented by K-pop male idols. A question about since when they have been into K-pop was also included in order to find out how long they have been exposed to the music scene and to interpret their familiarity to the idols. The rest of the questions will be further elaborated in result and discussion part.

All of the respondents are Indonesian and female in their 20s, and mostly are in college and working. The reason why the writer chooses twenty-something female is because of the assumption that they have more knowledge about gender issues and various gender images as portrayed in media and popular culture. Also, for practical reason, the writer believe that they have thoroughly understood the meaning of words used in the questionnaire like 'masculine' and 'feminine', so the writer does not have to explain the terms in the questionnaire. After collecting answers from respondents, the data were analyzed using interpretative approach (Orlikowski \& Baroudi, 1991). Since this study focuses on a small group of respondents, it does not intend to generalize the opinion of fan girls but to interpret the answers as an individual's choice, thoughts, and perspective. 


\section{RESULTS AND DISCUSSIONS}

There are six questions asked to the respondents of this research. The questions are: (1) since when have you been into K-pop? (2) What do you like from K-pop? (music, choreography, appearance, etc.) (3) In your opinion, how important is the appearance for K-pop male idols? (4) What do you think about K-pop male idols in make-up and considerably feminine appearance? (5) Have you ever thought that K-pop male idols do not look macho/look too feminine? (6) Do you want to have a boyfriend or husband with the appearance like K-pop male idols?

The first question is "Since when have you been into K-pop?" This question is put first in order to find out for how long the respondents have been a fan of K-pop. This will also reveal for how long they have been exposed to hybrid gender identity in K-pop scene.

The second question is "What do you like from K-pop? (music, choreography, appearance, etc.).” It focuses particularly on what aspect they like from K-pop. Besides the options given, the respondents are also allowed to give other possible answers.

The third question is "In your opinion, how important is the appearance for K-pop male idols?" From this question, I would like to find out the significance of appearance for K-pop male idols from the female fans' perspective.

The fourth question is "What do you think about K-pop male idols in make-up and considerably feminine appearance?" Starting from this question, the writer narrows down the topic into the new form of masculinity as shown by K-pop male idols and how the fans perceive it. Do they like it? Are they surprised? Since this is an open question, the answers can come very variously.

The fifth question is "Have you ever thought that K-pop male idols do not look macho/look too feminine?" Question number five is related to question number four but focuses more on the degree of masculinity and whether the fans are fine with this form of soft masculinity.

The sixth question is "Do you want to have a boyfriend or husband with the appearance like K-pop male idols? The last question is more of a reflective question since I want them to relate the topic to their personal life. I would like to know whether their preference of males in real life is similar with their preference as fans.

For question number one, some of the fan girls had known K-pop before 2011 (the year considered as significant for the entrance of K-pop culture into Indonesia, as mentioned in the introduction). Ferina, for example, has been familiar with a female Korean singer BoA's music and videos since 2002, but she answered that late 2012 as the year she got really into BIG BANG, her most favorite K-pop group. Another fan girl, Sarah, has been into K-pop since 2005 when she first knew Super Junior. Meanwhile, a respondent from Semarang, Mayang said she first got into K-pop in 2012 when BIG BANG's popularity started to get global with their album Alive. From twenty respondents, thirteen fan girls had known K-pop way before it got hugely famous in Indonesia, while the rest of them found out about K-pop after the local media started to expose the music and the culture in 2011.

Moving on to question number two, which is about what aspect they like the most from K-pop, the answers come variously. Ira from Bandung straightly answered that music is the aspect she likes the most, while Wangi from Bogor admitted that K-pop is interesting to observe for the detailed and intricate dance choreography. On the other hand, Jessica (from Depok) and Sarah stated that they like K-pop as a whole package; music, choreography, appearance, and the attractiveness of the group members. K-pop itself is indeed more than a music genre since it pays a lot of attention to visual aspects such as music videos, album designs, and fashion.

In question number three, the writer starts to focus more on the visual element of K-pop, particularly the appearance of K-pop male idols. It specifies only for K-pop male idols since the main topic for this article is soft masculinity as represented by K-pop male idols. According to Kunti, a fan of 2PM, physical appearance is an important thing onstage since it is a part of the concept that they present as performers. Even though she said that she does not really care about idols' appearance off-stage and off-camera, she highlights that the male idols need to pay attention to appearance in public because they will always be in the spotlight. Siska, as a fashion student, also believes that appearance has important values since it will be the first thing judged by the public. Ferina even elaborates that appearance is a part of Korean culture. Basically, all respondents understand that not only female idols are judged on their appearance, but male idols are also judged on their appearance. That is why companies will dedicate more effort to enhance the physical appearance of their male talents, starting from giving them designer's clothes to extreme ways like plastic surgery.

Questions number four and five narrows down the topic even more by relating it to gender identity. As stated by Sun Jung in Tunstall (2014), K-pop represents a new form of Korean masculinity, soft masculinity, as seen from their appearance. Through question number four and five, the writer would like to see how the fan girls perceive this new form of soft masculinity, whether they accept it or in a way are questioning it. The answers to question number four and five will be discussed together as the questions that are related to each other.

One respondent, Mayang, stated that she does not mind seeing male idols in make-up and considerably feminine appearance since she realized that it is necessary for performers to look attractive on stage. Jessica also seems to agree with Mayang's answer and adds that it is not strange anymore to see men in make-up, especially if they are performers or TV personalities. Furthermore, she explains that in Indonesia heavily groomed men are already a common phenomenon in urban lives, so she does not feel it is awkward. However, even though she does not mind feminine-looking male idols, she stated that for them they do not look manly. As for Ferina, she wished that the male idols could tone down their makeup a little bit since she thinks their make-up on stage is too thick. From Jessica and Ferina's answers, it can be interpreted that for them the appearance is a signifying feature to determine someone's level of manliness. Corporeality is still seen as a basic factor of someone's masculinity. This agrees with the essential thoughts that sex (biological features) is the most important element in confirming someone's identity.

Butler (1990) has stated that gender is a performance, which means it is always a doing, instead of merely being. A number of answers from the respondents, they seem to agree with Butler's previous statement. For instance, Ira from Bandung said she has no problem with male idols looking too feminine because she understands that it is only for stage necessity. While Wangi from Bogor also mentioned those male idols' feminine look is a part of marketing strategy from the agencies. Another respondent, Ajeng, claims that 
the feminine appearance is acceptable, depending on what occasion and for what purposes. Those answers convey that masculinity and femininity can be modified to meet a certain purpose, in this case for entertainment business purposes.

Another fan girl, Yanti, has an opinion that masculinity or femininity cannot be determined simply from physical appearance. Personality and attitude are also significant factors in perceiving someone's masculinity. What I could interpret from Yanti's answer is that modern masculinity has a complex definition. If in the past physical appearance seemed to be the absolute aspect in seeing a person's gender identity, now there are many other aspects involved. In K-pop male idols' case, just because they wear makeup and look pretty, it does not necessarily mean they are not masculine.

From their answers to question number five, I also can see how some respondents are aware of and critical to the traditional definition of gender. Sonia, working in a law firm, answered femininity in men should not be seen as something negative. In addition, she said that the concept of macho or feminine puts people into boxes with an intention to force them to fit a certain gender role. Meanwhile, Wangi comes with an answer that gender identity should not be judged, by stating that "Who are we to judge on how they present themselves?" From these answers, the writer concludes that in society gender has always been a controversially rigid categorization, and these fan girls try to oppose that strict definition and not to assess people from the gender identity they present.

In question number six, the writer wants them to relate the topic to their personal preference. The answers that writers found are interesting as a number of respondents said that their preference of males in real life is totally different from their preference as fan girls. It is interpreted that this difference could happen since they understand that K-pop idols' soft masculinity is presented only as a part of the entertainment business and for performance purposes. Thus, it cannot be applied or acted in daily life or activities.

Renny who is working in an advertising company, directly stated that she does not prefer to have a boyfriend or husband who looks like a K-pop idol. Her reason is that she prefers men who do not wear make-up at all. Cahya also has the same opinion. Since she considers herself as the super tomboy, she feels she cannot cope with guys who are too busy with beauty routines. Cahya's answer can be understood since she states that she prefers macho-looking idols like Big Bang than the feminine-looking ones like Seventeen. Next, Kunti also confesses she would not feel comfortable if having a feminine-looking partner because she is afraid he will look better than her. Their answers suggest that men should not look more beautiful than women. Here, it can be seen there is a distinction between their preference as fan girls and as a potential girlfriend or wife.

\section{CONCLUSIONS}

Since 2011, K-pop has become a significant popular culture in Indonesia, and this fact itself makes K-pop deserve an observation from an academic point of view. Through this paper, the writer is trying to offer a different perspective to this phenomenon, particularly in relation to gender issues. The analysis gives an interesting conclusion about how fangirls perceive soft masculinity.

From the analysis of the answers given by the respondents, there are three points that can be concluded. First, some of the answers reveal that the respondents do not mind seeing male idols in make-up and feminine appearance since they are aware that this is a part of marketing strategy and visual concepts. Second, the respondents also understand that appearance is not the only aspect that shapes masculinity. There are other factors that can determine someone's gender identity, such as personality and daily behaviors. However, this point needs more elaboration since the respondents do not mention what kind of personality and behavior that they consider as masculine. The last point that related to the first point where the respondents prefer not to have partners who look like K-pop idols. For them, makeup and feminine appearance are tolerable only if they are applied on stage, but not in daily life.

To conclude, popular culture has a significant role in shaping the representation of gender identity. K-pop has shown a new form of masculinity (soft masculinity) through the considerably feminine appearance of the male idols. However, the fans have their own perspective and opinion in responding to this non-traditional kind of masculinity. It all depends on their personal values and the environment that shapes their gender values. One thing for sure, the fan girls are conscious that this East Asian soft masculinity is nothing more than a kind of performance on stage.

\section{REFERENCES}

Beynon, J. (2002). Masculinites and Culture. Buckingham: Open University Press.

Bok-rae, K. (2015). Past, Present, and Future of Hallyu (Korean Wave). American International Journal of Contemporary Research, 5(5), 154-160.

Butler, J. (1990). Gender Trouble. New York: Routledge.

Connell, R. W., \& Messerschmidt, J. W. (2005). Hegemonic Masculinity: Rethinking the Concept. Gender \& Society, 19(6), 829-859. doi: http://doi. org/10.1177/0891243205278639

Fuhr, M. (2015). Globalization and Popular Music in South Korea: Sounding K-pop. London and New York: Routledge.

Gauntlett, D. (2002). Media, Gender and Identity. London and New York: Routledge.

Jang, G., \& Paik, W. K. (2012). Korean Wave as Tool for Korea's New Cultural Diplomacy. Advances in Applied Sociology, 2(03), 196-202. doi: http://doi. org/10.4236/aasoci.2012.23026

Kim, A. E., Mayasari, F., \& Oh, I. (2013). When tourist audiences encounter each other: Diverging learning behaviors of K-pop fans from Japan and Indonesia. Korea Journal, 53(4), 59-82.

Leung, S. (2012). Catching the K-pop Wave: Globality in the Production, Distribution, and Consumption of South Korean Popular Music. Senior Capston Project (Master Thesis).

Orlikowski, W. J., \& Baroudi, J. J. (1991). Studying Information Technology in Organizations: Research Approaches and Assump- tions. Information Systems Research, 2(1), 1-28.

Otmazgin, N., \& Lyan, I. (2014). Hallyu across the Desert: K-pop Fandom in Israel and Palestine. Cross-Currents: East Asian History and Culture Review, 3(3), 32-55. doi: http://doi.org/10.1353/ ach. 2014.0008 
Tunstall, E. D. (2014). Undesigning Masculinities: K-pop and the New Global Man. The Conversation. Retrieved from http://theconversation.com/undesigning-masculinities-k-pop-and-the-new-globalman-22335 